\title{
然 \\ DISSERTAÇÕES DE MESTRADO DEFENDIDAS EM 2019 NO MESTRADO PROFISSIONAL EM PODER LEGISLATIVO
}

CARVALHO, Miller Borges Castanheira de. Necessidades e competências em informação percebidas pelos secretários executivos das comissões permanentes da Câmara dos Deputados. Dissertação (Mestrado em Poder Legislativo). Câmara dos Deputados, Centro de Formação, Treinamento e Aperfeiçoamento (Cefor). 2019. 128f.

Orientador: Prof. Dr. Roberto Campos da Rocha Miranda

Resumo: A presente pesquisa exploratória objetivou avaliar a percepção dos Secretários Executivos das Comissões Permanentes da Câmara dos Deputados quanto às competências informacionais e às necessidades de informação por meio da utilização dos padrões australianos e neozelandeses de competências em informação. Partiu-se da premissa de que a atividade estudada é baseada fortemente no trato com a informação e tem estreita ligação com o ciclo informacional e, por isso, poderia ser abordada a partir de parâmetros da Ciência da Informação. O suporte teórico para a pesquisa baseou-se em áreas das Ciências da Informação e das Ciências Políticas. O estudo descritivo qualiquantitativo utilizou-se de pesquisa bibliográfica e da aplicação de questionário como métodos de investigação. A exploração inicial de alguns fenômenos informacionais que permeiam o Legislativo e a ampliação da compreensão das Ciências da Informação neste processo é tarefa crucial, isso porque a Câmara dos Deputados é instituição reconhecidamente produtora e consumidora de informação em toda a sua estrutura, e os Secretários executivos, foco do estudo, desempenham papel de relevância no processo legislativo. Os resultados mostram que os Secretários executivos podem ser considerados competentes em informação, pois têm noção das necessidades informacionais, buscam informação de forma satisfatória, avaliam e usam a informação na solução de problemas e apresentam postura crítica sobre as atividades informacionais. Além do mais, têm consciência da estrutura do mundo informacional que os rodeia, conhecem as estruturas de comunicação, têm fontes de informação semelhantes e demonstram certo padrão no trato com a informação. A análise dos resultados também demonstrou um alto grau de concordância dos Secretários Executivos quanto aos padrões utilizados, o que permitiu a exploração da hipótese de que os padrões australianos e neozelandeses utilizados ao longo do estudo subestimam as capacidades do público alvo.

Palavras-Chave: Competência em informação. Necessidade informacional. Secretário executivo. Comissão permanente. Câmara dos Deputados. Padrões de competência em informação. Poder Legislativo. 
MACHADO, Marilda Marcondes. Participação ou segurança: é preciso escolher? uma análise sobre o regulamento de acesso de visitantes à Câmara dos Deputados. Dissertação (Mestrado em Poder Legislativo). Câmara dos Deputados, Centro de Formação, Treinamento e Aperfeiçoamento (Cefor). 2019. 152f.

Orientador: Prof. Dr. Valério Augusto Soares de Medeiros

Resumo: A Câmara dos Deputados tem construído junto à sociedade, ao longo do tempo, a imagem de Parlamento aberto à presença dos cidadãos e de espaço para atividades de engajamento político. É frequentemente citada, em discursos legislativos e manchetes da imprensa, como "Casa do Povo". De fato, em momentos históricos relevantes do país, a instituição é palco de grandes manifestações populares e, diariamente, expressivo número de pessoas comparece à Casa para praticar atividades como acompanhar audiências públicas ou discussões de temas em votação, reunir-se com Parlamentares e protestar. Com base nesta premissa, o objetivo da dissertação é analisar o desenho normativo que regula o acesso de visitantes na Câmara dos Deputados, observando regras formais e informais, e as transformações que essas normas sofreram diacronicamente. Pretende-se avaliar os potenciais efeitos sobre as atividades de participação popular praticadas por cidadãos que comparecem à Casa, em razão do conflito que parece existir entre um Parlamento aberto e um conjunto de regras informais que restringem o acesso de cidadão por questões de segurança. A pesquisa, de natureza exploratória, é baseada em estudo de caso estruturado em levantamento bibliográfico/documental, entrevistas e questionários. Os achados apontam que as regras informais editadas pelo Depol têm reflexos sobre as atividades de participação que os cidadãos que frequentam a Casa exercem, mas que não são totalmente incompatíveis com a imagem da Câmara enquanto Parlamento aberto e próximo ao povo.

Palavras-Chave: Participação Popular. Visitantes. Regras de Acesso. Casa do Povo. Departamento de Polícia Legislativa. Câmara dos Deputados. Poder Legislativo.

CARVALHO, Maria do Socorro Dias Aires de. Relação entre satisfação do servidor e atividades desenvolvidas nas comissões permanentes da Câmara dos Deputados. Dissertação (Mestrado em Poder Legislativo). Câmara dos Deputados, Centro de Formação, Treinamento e Aperfeiçoamento (Cefor). 2019. $119 f$.

Orientador: Prof. Dr. Roberto Campos da Rocha Miranda. 
CÔRTES, Clemar Pereira Gonçalves da Silva. Para além do resultado das votações: Ressignificação do Propósito e da Eficácia de Audiências Públicas em Comissões Permanentes da Câmara dos Deputados, mediante Estudo de Caso. 2019, 149 f. Dissertação (Mestrado em Poder Legislativo). Câmara dos Deputados, Centro de Formação, Treinamento e Aperfeiçoamento (Cefor).

Orientadora: Profa. Dra. Malena Rehbein Sathler.

Resumo: À luz do Neoinstitucionalismo Histórico e Sociológico, a presente pesquisa defende a ideia de que a aferição do nível de sucesso das audiências públicas realizadas em sede de comissão permanente da Câmara dos Deputados está diretamente relacionada à correta delimitação dos diferentes propósitos por elas perseguidos. Face às distintas finalidades que eventualmente apresentem, sublinha-se o equívoco de se rotularem reuniões dessa natureza como pouco eficazes, sob a acusação de pouco interferirem sobre o resultado das votações legislativas. Destarte, procedeu-se ao estudo de caso das reuniões realizadas pela Comissão de Minas e Energia da Casa durante a $54^{\mathrm{a}}$

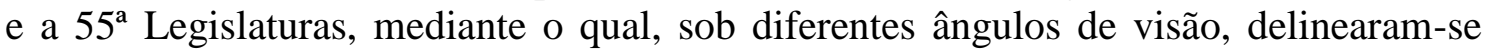
propósitos factíveis, a partir dos quais se devam medir os respectivos níveis de eficácia. Extraiu-se, então, que a participação política constitui princípio, cultura e propósito das audiências públicas, decorrente de path dependence das transformações históricas do modelo representativo de governo. Assim, a garantia da participação política mediante vias formal e informalmente institucionalizadas, per si, já atesta a eficácia do instituto. Ademais, apurou-se que as reuniões examinadas pouco se referiram a projetos de lei em tramitação: entre contornos distributivistas e informacionais, as audiências públicas apresentaram finalidade eminentemente fiscalizatória - missão do Poder Legislativo pouco enfatizada por estudos aplicados, no que respeita a sua relevância pública.

Palavras-Chave: audiência pública, comissão, participação, representação, institucionalismo, notícia.

SILVA, Beatriz Simas Silva. Medidas provisórias e diálogo entre poderes: a articulação dos pressupostos constitucionais de relevância e urgência e a organização do processo legislativo após a Emenda Constitucional $n^{\circ}$ 32, de 2001. 2019. $269 \mathrm{f}$. Dissertação (Mestrado em Poder Legislativo) - Câmara dos Deputados, Centro de Formação, Treinamento e Aperfeiçoamento (Cefor).

\section{Orientador: Prof. Dr. Júlio Roberto de Souza Pinto}

Resumo: A Constituição de 1988 permite ao Presidente da República editar medidas provisórias, que são atos com força de lei e produzem efeitos imediatos, diante de situações reputadas como relevantes e urgentes. As medidas provisórias devem ser apreciadas pelo Congresso Nacional em até 120 dias, sob pena de perda de eficácia. Tradicionalmente, sucessivos governos têm feito amplo uso das medidas provisórias para implementar suas agendas de governo e existe grande debate em torno de como os pressupostos constitucionais de relevância e urgência são realmente atendidos. O objetivo deste trabalho é analisar o uso das medidas provisórias no período de 2001 a 2018 e, à luz da teoria do discurso de Ernesto Laclau e das teorias de diálogo institucional, avaliar como tem ocorrido a deliberação, no âmbito dos Três Poderes, quanto à relevância e urgência das medidas provisórias editadas. Os resultados obtidos demonstram que as medidas provisórias foram utilizadas predominantemente para tratar de matérias econômicas, fiscais e tributárias. Entretanto, a fundamentação das medidas provisórias variou significativamente, de acordo com a orientação política de cada governo e do momento do ciclo econômico, reforçando a importância das práticas articulatórias para a 
construção dos significados de relevância e urgência. Quanto à atuação do Poder Judiciário, destaca-se ao longo do período a forte interferência em questões relacionadas ao processo legislativo de conversão de medidas provisórias que, contudo, podem ser superadas pelo Poder Legislativo por meio de emendas constitucionais.

Palavras-Chave: Poder Legislativo. Poder Executivo. Poder Judiciário. Medidas Provisórias. Direito Constitucional. Teorias do Diálogo Institucional. Teorias do Discurso

CARDOSO, Abraham Lincoln Ferreira. A regulamentação do lobby no parlamento brasileiro: uma abordagem e análise da construção legislativa da regulamentação da atividade. 2019. 269 f. Dissertação (Mestrado em Poder Legislativo) - Câmara dos Deputados, Centro de Formação, Treinamento e Aperfeiçoamento (Cefor).

\section{Orientador: Prof. Dr. Ricardo Chaves de Rezende Martins}

Resumo: Em determinados momentos na vida da sociedade brasileira, o tema do exercício da atividade de lobby no país tem ganhado destaque. Esse interesse reflete nas discussões no âmbito do parlamento brasileiro. Entretanto, até a presente data ainda não se tem uma lei que regulamente o exercício desta atividade no Brasil. A falta desta regulamentação específica, embora o parlamento se debruce sobre algumas proposições em tramitação sobre o tema, e a proporcional carência de estudos recentes sobre o tema, certamente justificam este trabalho de pesquisa. A pesquisa se insere no campo do estudo dos grupos de interesse e na seara temporal e temática sobre a regulamentação do lobby. Tem como objetivo geral evidenciar a evolução no processo de regulamentação da atividade de lobby e como objetivos específicos: (i) realizar um breve histórico das proposições legislativas sobre o tema; (ii) analisar a tendência da força normativa dos textos em tramitação, para verificar seu enquadramento em fraca, média ou forte, de acordo com a metodologia utilizada por Chari, Murphy e Hogan (2007); e (iii) identificar a percepção dos profissionais de Relações Institucionais e Governamentais (RIG) quanto aos itens presentes no texto normativo em construção. Este trabalho se insere no campo das pequisas quali-quantitativa e utilizou-se de levantamento bibliográfico e documental, bem como de uma pesquisa realizada junto a profissionais que atuam na defesa de interesses com o intuito de levantar a percepção sobre os tópicos constantes nos textos em construção sobre a regulamentação da atividade de lobby. Como resultado deste trabalho de pesquisa observou-se que foram apresentadas inúmeras proposições sobre o tema, que o texto normativo em construção está tendente a ser uma legislação com viés fraco, no tocante a sua força normativa e que é possível inferir que as percepções dos respondentes coincidiram com os tópicos presentes e ausentes no texto normativo em construção até o presente momento.

Palavras-Chave: Poder Legislativo. Câmara dos Deputados. Lobby. Defesa de interesses. Grupos de interesses. Regulamentação do lobby. 
BARROS, Caio Carvalho Correia. Discurso populista na república liberal: análise de discursos e o conceito de populismo. 2019. 101 f. Dissertação (Mestrado em Poder Legislativo) - Câmara dos Deputados, Centro de Formação, Treinamento e Aperfeiçoamento (Cefor).

Orientadora: Profa. Dra. Cristiane Brum Bernardes.

Resumo: Este trabalho busca compreender a maneira pela qual o populismo se manifesta em discursos políticos proferidos no contexto das República Liberal - período da história política brasileira que vai de 1946 a 1964. Para entender o populismo como um tipo específico de linguagem política, inicialmente, analisamos o conceito a partir do estudo de três dimensões teóricas: 1) a dimensão ideacional, 2) a dimensão de parte da sociologia brasileira e 3) a dimensão da filosofia política de Ernesto Laclau. Então, estabelecemos "elementos populistas" para, a partir de um plano de leitura qualitativo de pronunciamentos de Getúlio Vargas, de João Goulart e de Carlos Lacerda, identificar neles a eventual presença de "elementos populistas". Ainda, a conjuntura política e social do período em tela foi percorrida para destacarmos a relação entre linguagem e prática social. Dessa forma, concluímos que a análise de discursos pode ser um bom meio de se analisar e problematizar conceitos, como o de populismo.

Palavras-chave: Populismo. República Liberal. Análise de Discurso. Discurso Populista. Poder Legislativo.

COELHO, Cidney Arantes Carrasquel. A história da gestão de riscos na câmara dos deputados: o caminho percorrido para implantação do processo nessa casa legislativa. 2019. 84 f. Dissertação (Mestrado em Poder Legislativo) -- Câmara dos Deputados, Centro de Formação, Treinamento e Aperfeiçoamento (Cefor).

Orientador: Prof. Dr. João Luiz Pereira Marciano.

Resumo: O presente trabalho relata a história do surgimento da gestão de riscos corporativos na Câmara dos Deputados até a promulgação de sua política, através do Ato da Mesa n. 233, de 2018. Por meio de uma pesquisa documental e entrevistas semiestruturadas, pretendeu-se historiar os fatos relevantes ocorridos na implantação da política da gestão corporativa de riscos nessa Casa, haja vista, que a partir de uma investigação de fatos passados consegue-se descobrir e registrar as experiências adquiridas, as quais podem vir a ajudar a administração no futuro. Constatou-se que o Tribunal de Contas da União (TCU) foi o grande indutor para adoção desse processo, apesar de haver uma parcela de servidores públicos que acreditam que essas interferências não seriam competência da Corte de Contas. Cabe destacar que o projeto de implantação desse processo de gestão é um exemplo a ser seguido pela administração. Outrossim, as ações, nessa Casa do Poder Legislativo, para a efetiva implantação do gerenciamento de riscos estão sendo implementadas em algumas unidades e, assim, a cultura de riscos vem se concretizando. Verificou-se também a pertinência do uso do COSO ERM, de 2017, como base teórica para as entrevistas realizadas e para o estudo dos dados documentais levantados. Este trabalho expõe algumas lições aprendidas nesse caminho percorrido e, também, retrata a percepção de alguns gestores dessa Casa Legislativa sobre a possibilidade da efetiva implantação do gerenciamento de risco. 
Palavras-chave: Gestão de Riscos. Poder Legislativo. COSO ERM. Câmara dos Deputados.

FREITAS, Eduardo Antônio Mello. A inteligência artificial na tradução automática de documentos legislativos: uma aplicação na pesquisa interparlamentar. 2019. $132 \mathrm{f}$. Relatório Técnico-Científico (Mestrado em Poder Legislativo). Câmara dos Deputados, Centro de Formação, Treinamento e Aperfeiçoamento (Cefor).

Orientador: Prof. Dr. Fabiano Peruzzo Schwartz

Resumo: O desenvolvimento da pesquisa interparlamentar é uma forma de fortalecer a democracia por meio da cooperação entre os parlamentos. O grande volume de documentos disponibilizados apenas nas línguas oficiais é um obstáculo à pesquisa interparlamentar e à abertura mais ampla de dados. O presente trabalho tem como principal objetivo analisar a viabilidade do uso da tradução automática com vistas a facilitar a busca de conteúdo de documentos legislativos e a tornar a pesquisa legislativa menos dependente da língua. O método consiste no desenvolvimento de um tradutor automático com o uso de inteligência artificial cujo treinamento se dá a partir de documentos previamente tratados pertinentes ao Poder Legislativo; em extração de dados de sites e documentos legislativos; em pesquisa bibliográfica ampla com a finalidade de selecionar as técnicas e modelos de redes neurais artificiais mais utilizados na tradução automática; em testes de laboratório acompanhados de ajustes de parâmetros e aferição de desempenho; na apresentação em reunião perante representantes de parlamentos membros e grupos parlamentares da União Interparlamentar. O relatório introduz conceitos básicos de redes neurais relacionados aos principais modelos utilizados no desenvolvimento de tradutores automáticos e explica o preparo dos documentos. Das 8 milhões de sentenças extraídas de documentos legislativos da União Europeia, pouco mais de 5 milhões foram utilizadas nos treinamentos. O melhor resultado de treinamento alcançou 92\% de acurácia na validação cruzada, o que motivou o uso da tradução automática, tanto no Brasil como em outros países, com a finalidade de disponibilizar dados e documentos legislativos em outras línguas. Conclui-se, portanto, que a tradução automática especializada cumpre com o propósito de comunicar a essência de textos legislativos e de criar novas oportunidades de pesquisa e troca de experiência entre os parlamentos e a sociedade civil mundial, respeitada a autodeterminação dos povos.

Palavras-chave: Tradução Automática Especializada. Cooperação Interparlamentar. Poder Legislativo. Inteligência Artificial. Pesquisa Interparlamentar. 
VIANA, Lívia de Souza. O controle externo federal da agropecuária e meio ambiente: avaliação da atuação da Câmara dos Deputados e do Tribunal de Contas da União. 2019. 74 f. Dissertação (Mestrado em Poder Legislativo). Câmara dos Deputados, Centro de Formação, Treinamento e Aperfeiçoamento (Cefor).

Orientador: Prof. Dr. Maurício Schneider.

Resumo: O controle, entendido como a atividade destinada a comprovar a probidade da ação governamental, bem como a regularidade da guarda e do emprego de bens públicos, é função essencial ao pleno funcionamento do Estado Democrático de Direito. O controle externo, realizado por órgão localizado fora do Poder da instituição controlada, é função típica do Poder Legislativo brasileiro, que deve exercê-lo para garantir o alcance satisfatório dos interesses públicos, entre os quais está o direito fundamental ao meio ambiente ecologicamente equilibrado, conjuntamente à garantia da produção agrícola e ao abastecimento alimentar. Este trabalho se propôs avaliar a atuação do controle externo federal sobre o meio ambiente e a agropecuária, por meio do estudo de processos conduzidos pelo Tribunal de Contas da União (TCU) e pela Câmara dos Deputados (CD). A pesquisa envolveu o estudo de decisões emitidas pelo TCU entre os anos 2012 e 2018 e de todas as propostas de fiscalização e controle (PFC) conduzidas por comissões temáticas da CD desde 1988. Em cada processo e decisão estudada, foram identificadas as principais variáveis que compõem e influenciam os processos, as quais, em conjunto com as respectivas informações, compuseram banco de dados. Além de maior compreensão da operacionalização dos processos de controle, os dados coletados e as análises efetuadas permitiram concluir que o controle externo tem alcançado baixos níveis de efetividade, o que é evidenciado pela constatação recorrente das mesmas deficiências de gestão em órgãos e entidades da Administração Pública, ao longo de quase vinte anos. Entre as causas, estão as lacunas de regulamentação, tanto na $\mathrm{CD}$ quanto no TCU, e a utilização equivocada de técnicas e instrumentos de controle. Cita-se ainda a atribuição de pouca importância aos monitoramentos dos processos, os quais são realizados pelo TCU com intempestividade e pouca coercitividade. Diversas sugestões para aprimoramento dos problemas constatados foram apresentadas neste trabalho.

Palavras-chave: Controle Externo Federal. Poder Legislativo. Tribunal de Contas da União. Câmara dos Deputados. Meio Ambiente. Agropecuária.

CARVALHO, Miller Borges Castanheira de. Necessidades e competências em informação percebidas pelos secretários executivos das comissões permanentes da Câmara dos Deputados. 2019. 127 f. Dissertação (Mestrado em Poder Legislativo) -Câmara dos Deputados, Centro de Formação, Treinamento e Aperfeiçoamento (Cefor)

Orientador: Prof. Dr. Roberto Campos da Rocha Miranda.

Resumo: A presente pesquisa exploratória objetivou avaliar a percepção dos Secretários Executivos das Comissões Permanentes da Câmara dos Deputados quanto às competências informacionais e às necessidades de informação por meio da utilização dos padrões australianos e neozelandeses de competências em informação. Partiu-se da premissa de que a atividade estudada é baseada fortemente no trato com a informação e tem estreita ligação com o ciclo informacional e, por isso, poderia ser abordada a partir 
de parâmetros da Ciência da Informação. O suporte teórico para a pesquisa baseou-se em áreas das Ciências da Informação e das Ciências Políticas. O estudo descritivo qualiquantitativo utilizou-se de pesquisa bibliográfica e da aplicação de questionário como métodos de investigação. A exploração inicial de alguns fenômenos informacionais que permeiam o Legislativo e a ampliação da compreensão das Ciências da Informação neste processo é tarefa crucial, isso porque a Câmara dos Deputados é instituição reconhecidamente produtora e consumidora de informação em toda a sua estrutura, e os Secretários executivos, foco do estudo, desempenham papel de relevância no processo legislativo. Os resultados mostram que os Secretários executivos podem ser considerados competentes em informação, pois têm noção das necessidades informacionais, buscam informação de forma satisfatória, avaliam e usam a informação na solução de problemas e apresentam postura crítica sobre as atividades informacionais. Além do mais, têm consciência da estrutura do mundo informacional que os rodeia, conhecem as estruturas de comunicação, têm fontes de informação semelhantes e demonstram certo padrão no trato com a informação. A análise dos resultados também demonstrou um alto grau de concordância dos Secretários Executivos quanto aos padrões utilizados, o que permitiu a exploração da hipótese de que os padrões australianos e neozelandeses utilizados ao longo do estudo subestimam as capacidades do público alvo.

Palavras-chave: Competência em informação. Necessidade informacional. Secretário executivo. Comissão permanente. Câmara dos Deputados. Padrões de competência em informação. Poder Legislativo.

MENEZES, Vanildo da Cunha. Regime de competência contábil na Câmara dos Deputados: uma análise do processo de institucionalização do regime de competência contábil para o registro patrimonial na Câmara dos Deputados segundo a vertente sociológica do institucionalismo. 2019. 231 f. Dissertação (Mestrado em Poder Legislativo) -- Câmara dos Deputados, Centro de Formação, Treinamento e Aperfeiçoamento (Cefor).

Orientador: Nelson Gomes dos Santos Filho.

Resumo: As normas contábeis brasileiras para o setor público vêm passando por mudanças em um movimento de convergência às normas internacionais pela adoção do regime de competência contábil para o registro dos fatos que afetam o patrimônio. A pesquisa procurou entender como essa mudança está ocorrendo na contabilidade da Câmara dos Deputados à luz do institucionalismo sociológico. A teoria institucional contemporânea, nos estudos organizacionais, vem, desde a década de setenta, sendo utilizada para o entendimento das mudanças nos arranjos estruturais das corporações com uma reflexão ampliada do ambiente organizacional para além dos conceitos técnicos e destacando os aspectos simbólicos. Justifica-se o estudo pela oportunidade de conhecimento do estágio de implantação do novo regime contábil por um ente do perfil da Câmara dos Deputados. O objetivo da pesquisa foi descrever o processo de institucionalização do regime de competência contábil na Câmara dos Deputados. Para tanto, a pesquisa propôs a modelagem de Tolbert e Zucker (1998) que divide o processo em três fases: habitualização, objetificação e sedimentação. A metodologia utilizada foi descritiva e exploratória com procedimentos de pesquisa bibliográfica e documental, abordagem qualitativa e realização de entrevistas. Os dados coletados foram analisados e categorizados conforme os aspectos do processo. De forma geral, os resultados 
apontam que a Câmara dos Deputados se encontra no estágio de sedimentação do processo de institucionalização. A sedimentação é o último estágio do processo, o que caracteriza nível avançado de institucionalização do regime de competência contábil na Câmara dos Deputados.

Palavras-chave: Câmara dos Deputados. Institucionalismo sociológico. Poder Legislativo. Processo de institucionalização. Regime de competência 